\title{
МИНЕРАЛОГИЯ АГАТОВ В БАЗАЛЬТАХ СУЙСАРСКОГО ВУЛКАНИЧЕСКОГО КОМПЛЕКСА ЦЕНТРАЛЬНОЙ КАРЕЛИИ
}

\section{Светова Е.Н., Светов С.А.}

Институт геологии КарНЦ РАН, ФИЦ «Карельский научный иентр РАН», Петрозаводск, ensvetova@igkrc.ru

Палеопротерозойские суйсарские вулканиты, несущие агатовую минерализацию, развиты в пределах Онежской структуры Центральной Карелии на площади около 2 тыс. км ${ }^{2}$ [4]. Среди эффузивных пород доминируют пикробазальты, мелабазальты и базальты, локально встречаются трахибазальты и андезибазальты. Большая часть лавовых потоков сложена массивными лавами (местами переходящими в миндалекаменные разновидности) тонкозернистого строения, для многих потоков характерна подушечная и шаровая отдельность. Возраст пород суйсарского комплекса по $\mathrm{Sm}-\mathrm{Nd}$ изотопным данным составляет $1975 \pm 24$ млн. лет [3].

Агатовые образования можно встретить на некоторых островах Онежского озера, а также местами на его побережье. Первое описание халцедона с зональной структурой в базальтах острова Суйсари было приведено в трудах Императорского Санкт-Петербургского общества естествоиспытателей в 1912 г. В.М. Тимофеевым [5]. С тех пор опубликованные в литературе сведения об агатах суйсарского комплекса носят в основном лишь географический характер, что, собственно, и вызвало интерес специально обратиться к характеристике агатов некоторых известных нам проявлений. В настоящей работе приводятся новые минералогические сведения об агатовых образованиях из шарово-подушечных лав суйсарского вулканического комплекса Центральной Карелии, выполненного с использованием оптической и электронной микроскопии, микрозондового, рентгенодифракционного и рентгенофлюоресцентного анализов.

Основу исследований составила коллекция агатов и образцов вмещающих их базальтов, собранная авторами на трех удаленных между собой участках коренных выходов суйсарских вулканитов в северо-западной части бассейна Онежского озера: 1 - береговые обнажения Пиньгубы (район дачного поселка Пиньгуба); 2 - Ялгубская гряда (агаты обнаружены в лавовых потоках, вскрытых недавними горными работами при строительстве спортивного центра «Ялгора» приблизительно в центральной части горнолыжного склона; 3 - береговые обнажения о. Суйсари, мыс Кельтнаволок (Кондопожская губа). Во всех случаях агатовую минерализацию вмещают эффузивы, представленные подушечными лавами с массивными или миндалекаменными текстурами в ядрах подушек. Подушки имеют плотную упаковку, размер их варьирует от $0.3 \times 0.6$ м до $1.5 \times 2.5$ м, цемент представлен туфовым материалом с примесью терригенной составляющей. Агатовые образования встречаются в коренных выходах пород в виде выступающих желваков, выполняющих межшаровое пространство в подушечных лавах и тектонические трещины, заполняют газовые пустоты в базальтах. В большинстве случаев выделения агатов имеют конусовидную форму, обусловленную их выполнением межподушечного пространства, реже встречаются линзовидные, прожилковые формы. Размер таких выделений в поперечнике варьирует от 3-5 см до 50 см. В прибрежной зоне, особенно после штормов, агаты легко обнаружить в виде гальки и других обломков у воды.

Изучаемые вулканиты суйсарского комплекса по содержанию $\mathrm{SiO}_{2}$ и $\mathrm{Na}_{2} \mathrm{O}+\mathrm{K}_{2} \mathrm{O}$ могут быть отнесены к группе пикритов, базальтов, андезибазальтов нормальной щелочности и умеренно калиевой серии. Дифференциация пород на изучаемых объектах проявлена неоднородно, более основные вулканиты (пикриты) характеризуют Ялгубский разрез, их производные (андезибазальты, андезиты) широко распространены в районе Пиньгубы и о. Суйсарь. Пикрититы Ялгубы существенно обогащены $\mathrm{CaO}$ (9.5-16.0 мас. \%), что, скорее всего, связано с локальной гидротермальной проработкой вмещающих агатовую минерализацию вулканитов. Подтвержением данному наблюдению могут быть аномально высокие значения п.п.п. (до 14.3 мас.\%, при стандартных значениях 1.9-5.3 мас. \%). Для всех вулканитов характерны повышенные содержания $\mathrm{MgO}$ от 5.7 до 10.8 мас.\%, умеренные содержания: $\mathrm{FeO}^{*}$ от 8.3 до 11.2 мас. \% и $\mathrm{Al}_{2} \mathrm{O}_{3}$ от 9.3 до 15.1 мас. \%.

Агаты рассматриваемых проявлений, в целом не отличающиеся широкой цветовой палитрой 
и высокой художественностью рисунка, имеют между собой определенные различия, проявленные в особенностях морфологии, окраски, составе участвующих в их строении минералов, что обусловлено, вероятно, локальными особенностями вещественного и химического состава вмещающих пород.

Своеобразная окраска характерна для агатов проявления Пиньгуба (рис. 1, а): в основной массе агатовых выделений доминируют буровато-красные тона, что позволяет отнести их к карнеолагатам [3]. Характерной декоративной особенностью почти всех образцов проявления являются контрастные зеленые выделения хлорита. По конфигурации слоев макроскопической зональности агаты отвечают концентрически-зональному бастионному типу, встречаются также очковые (глазковые), моховые разновидности, а также выделения с неясно-рисунчатой макротекстурой [2, 3]. Количество чередующихся разноокрашенных полос в агатах обычно невелико, до 4-5 на 1 см, из-за наложенных трещин и развитых по ним налетов оксидов железа и других включений, декоративность рисунка часто снижена. Центральные части агатовых секреций обычно выполнены либо однородным мелкокристаллическим молочно-белым кварцем, либо чередующимися, в разной степени прозрачными слоями кварца и халцедона. Ширина таких слоев варьирует в широких пределах - от сотых долей миллиметра до сантиметров. В самых крупных миндалинах центральную часть слагает друзовый прозрачный кварц.

Для агатовых образований Ялгубской гряды характерно преобладание бесцветных, дымчатосерых и мятных оттенков (рис. 1, г). По морфологии и внутреннему строению агаты можно разделить на грубополосчатые линейно-концентрические и неясно-рисунчатые прожилковые; многие из них трещиноваты. Внешняя халцедоновая зона секреций, как правило, сильно пигменти-
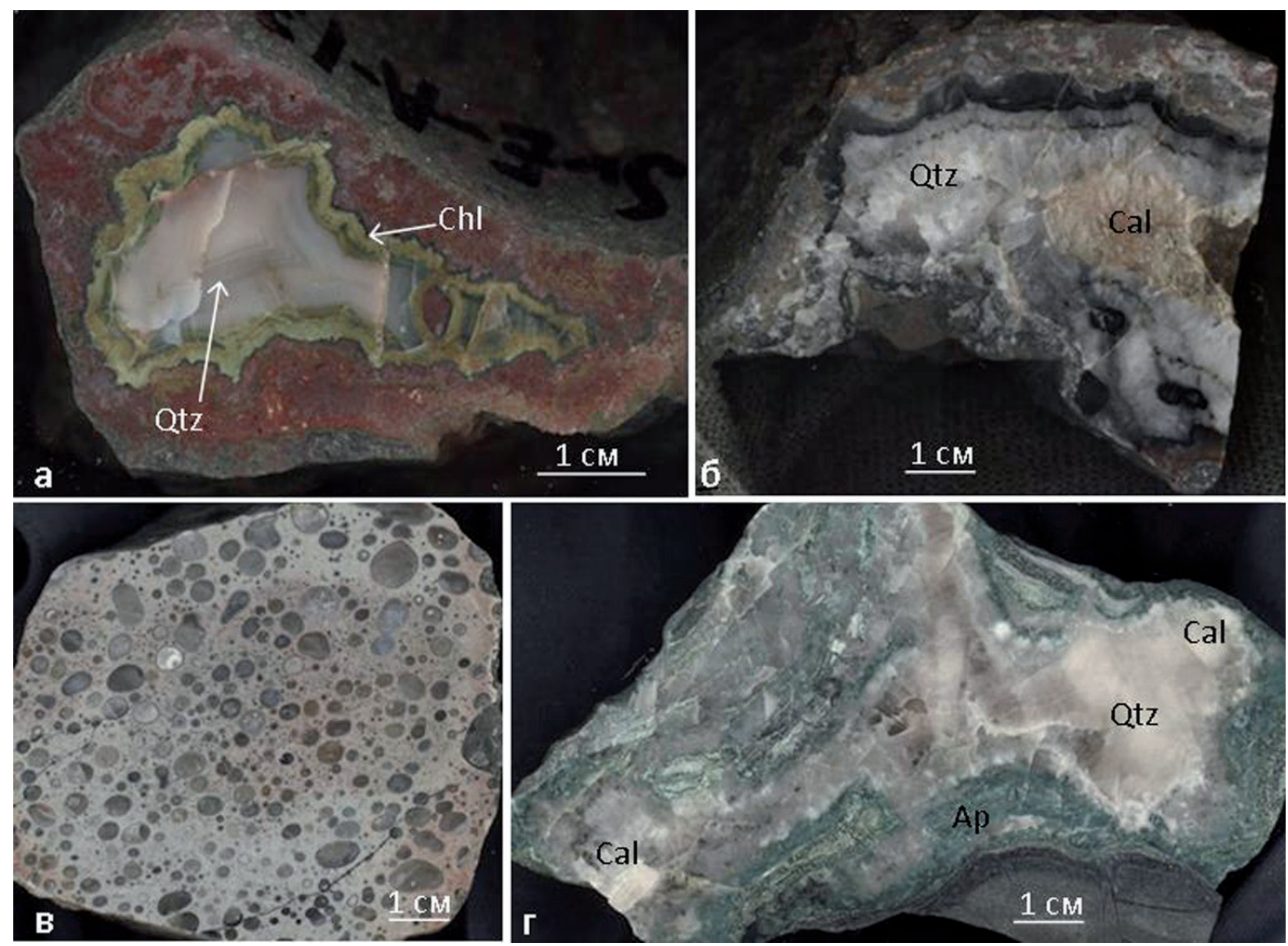

Рис. 1. Агатовые выделения в базальтах суйсарского вулканического комплекса.

a - конусовидная агатовая миндалина с облекающим типом зональности с характерной хлоритовой оторочкой (Пиньгуба); б - кварц-кальцитовая миндалина, пигментированная по периферии и локально в центральных частях рассеяным шунгитовым веществом (о. Суйсари); в - миндалекаменный базальт с газовыми пузырями, заполненными халцедоном; г-кальцит-халцедоновая миндалина с тонкораспыленными включениями апатита. 

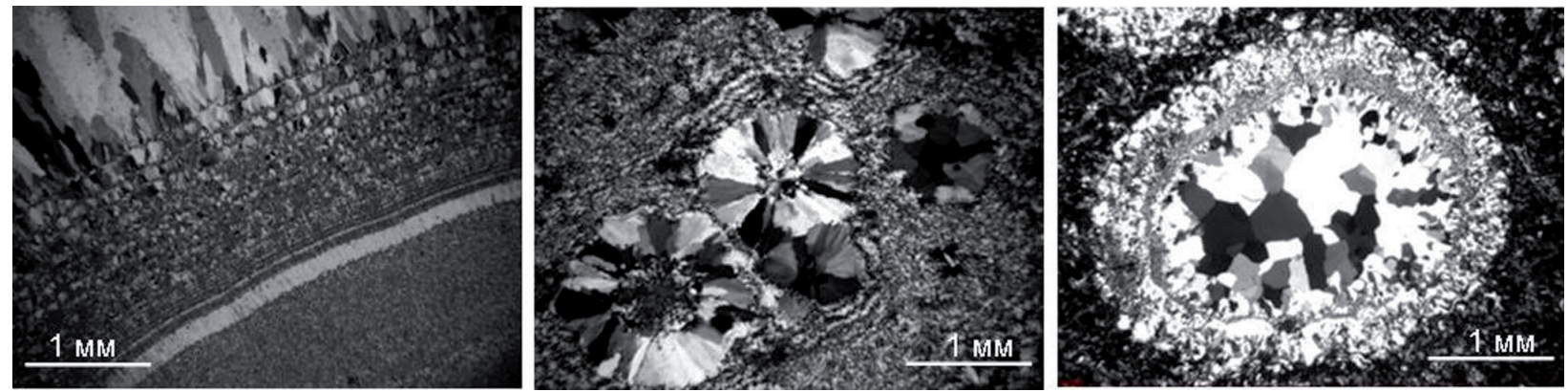

Рис. 2. Детали строения агатовых миндалин.

а- чередование зон глиноподобного и волокнистого халцедона, разнозернистого кварца в концентрическизональном агате, (Пиньгуба); б-сферолиты кварцина в чешуйчатом агрегате халцедона, (о. Суйсари); в-концентрическое строение агатовой миндалины в мандельштейне: внешняя зона мелкочешуйчатого халцедона сменяется зонами: глиноподобного халцедона, мелкозернистого и крупнозернистого кварца (Пиньгуба).

рована включениями апатита, обуславливая редкую мятную окраску. Внутренняя зона сложена прозрачно-серым кварц-халцедоновым агрегатом часто с микросферолитовой структурой, в редких случаях отмечается малоконтрастная тонкая полосчатость. Отличительной особенностью Ялгубских агатов является широко проявленная поздняя кальцитовая минерализация. Крупные кристаллы исландского шпата или дымчато-серого кальцита, почти полностью замещающие халцедон в центральной части секреций, обнаружены нами в большинстве агатовых выделений.

Минералогической особенностью агатов острова Суйсари, является присутствие в составе миндалин шунгитового вещества. По характерному однородному черному окрасу или причудливой формы черно-белому рисунку их называют иногда черными агатами (рис. 1, б). Светлые зоны в них, выполненные халцедоном и кварцем, чередуются с черными участками, где халцедон или кварц пигментирован рассеянным шунгитовым веществом, находящимся в промежутках между зернами кварца, или в виде ультратонких нитевидных выделений рассеянным в халцедоне. В ряде случаев кварцевые агатовые секреции содержат крупные выделения кальцита, замещающие халцедон, в том числе в виде крупных до 2-4 см кристаллов, иногда расщепленных, вплоть до груболучистых сферолитов.

Изучение шлифов тонкополосчатых агатов под микроскопом в проходящем свете показало, что выделяемые визуально слои обладают различной микротекстурой. Они сложены разнозернистыми агрегатами кварца, мелкочешуйчатого и волокнистого халцедона, в ряде случаев отмечаются волокна и сферолиты кварцина (рис. 2).

Отмечаемые в миндалекаменных базальтах суйсарского комплекса минерализованные газовые пузыри имеют преимущественно округлые очертания и заполняют до 10 \% объема породы. Размер пузырей варьирует от 0.1 до 1-2 см. Центральные части миндалин в большинстве случаев заполнены крупнозернистым агрегатом чистого кварца. В периферических частях между кварцевыми зернами рассеяны пылевидные частицы магнетита, иногда снаружи миндалина окаймлена хлоритом. Для многих миндалин свойственна концентрическая зональность, где роль чередующихся
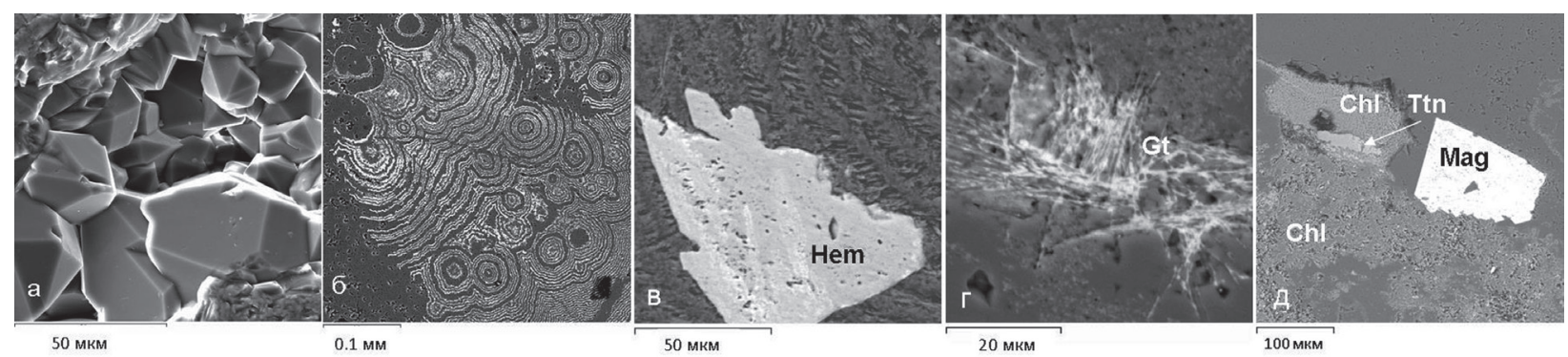

Рис. 3. Электронно-микроскопические изображения.

a - скульптуры сколов кварц-халцедоновой зоны агатов; б - псевдоморфозы эпидота (светлое) по кремнезему (темное) в текстуре агата; в - микронеоднородное включение гематита (Hem), г- игольчатые кристаллы гетита (Gt), д - титанит(Ttn) и магнетит (Mag) в ассоциации с хлоритом (Chl). 
полос в них выполняют тончайшие слои разноструктурированного халцедона и кварца (рис. 2, б).

При рентгенографическом изучении образцов из неокрашенной силикатной части агатовых секреций на дифрактограммах были установлены лишь отражения $\alpha$-кварца, иных форм кремнезема (опала, кристобалита, тридимита, и др. ) не обнаружено. Расчет параметров элементарных ячеек кварца, выполненный по 10 образцам кварцевых миндалин показал достаточную стабильность значений: $\mathrm{a}=4.9134 \pm 0.003 \AA, \mathrm{b}=5.4054 \pm 0.003 \AA, \mathrm{V}=113.01$. Индекс рентгеновской кристалличности агатового кварца, измеренный по известной методике [6], варьирует от 7.08 до 8.06, что указывает на высокую упорядоченность его структуры. Агатовый кальцит (Ялгуба), по данным рентгенографии, чистый, не содержит посторонних минеральных фаз и характеризуется следующими параметрами элементарной ячейки: бесцветный - $\mathrm{a}=4.9866 \AA, \mathrm{b}=17.0413 \AA, \mathrm{V}=366.99 \AA$; дымчатый $-\mathrm{a}=4.9907 \AA, \mathrm{b}=17.0647 \AA, \mathrm{V}=368.09 \AA$.

Электронно-микроскопическое изучение поверхности сколов кварц-халцедоновых агрегатов секреций при увеличениях до 8 тысяч раз показало, что отдельные слои в изломе обладают различными внутренними микротекстурами. Наиболее типичными для исследованных агатов являются структуры, обусловленные развитием индивидов кварца размером от 3 до 50 мкм с четкими кристаллографическими очертаниями (рис. 3 , а).

Микрозондовым исследованием были установлены основные и акцессорные минеральные фазы в агатах рассматриваемых проявлений (рис. 3, б-д). Хлорит, обуславливающий зеленые мотивы окраски агатов, характеризуется высокой стабильностью состава в пределах изученной группы агатов и относится к магнезиально-железистой разновидности. В отдельных зонах агатов всех проявлений широко проявлено присутствие микровключений оксидов и гидроксидов железа, различающихся степенью окисления железа и степенью гидратации (магнетит, гематит, гетит). В кварцевых прослоях агатов установлены многочисленные микроминеральные фазы, отвечающие по составу эпидоту, мусковиту, кальциту, гидроксилапатиту, титаниту, пириту, халькопириту, альбиту, хлориту.

Таким образом, минералогия агатов рассматриваемых проявлений достаточно своеобразна и представлена силикатами, окислами и гидроокислами, сульфидами и карбонатами. Основную роль в строении агатов выполняют минералы семейства кремнезема - мелкокристаллический кварц и волокнистый халцедон. Агатовая минерализация, пространственно и генетически связанная с районом проявления базальтового вулканизма палеопротерозойского возраста, образована на поздних стадиях становления базальтового покрова из сравнительно низкотемпературных гидротермальных растворов, о чем свидетельствует частый парагенезис кварца с кальцитом и другими низкотемпературными минералами. Отсутствие параллельно-слоистых агатов в суйсарских базальтах, вероятно, указывает на относительно низкую концентрацию кремнекислоты в гидротермальных растворах, препятствующей процессу гравитационного осаждения коллоидной составляющей. Описанные агатовые проявления являются интересными и доступными для посещения минералого-геологическими объектами, дающими возможность знакомства с агатоносными породами, в том числе студентамгеологам, проходящим учебную практику вблизи г. Петрозаводска.

Исследования выполнены в рамках госзадания КарНЦ РАН (тема №210).

\section{Литература}

1. Барсанов Г.П., Яковлева М.Е. Минералогия поделочных и полудрагоценных разновидностей тонкозернистого кремнезема. М.: Наука. 1984. 144 с.

2. Годовиков А.А., Рипинен О.И., Моторин С.Г. Агаты. М.: Недра. 1987. 368 с.

3. Пухтель И.С., Богатиков О.А., Куликов В.С., Куликова В.В., Журавлев Д.З. Роль коровых и мантийных источников в петрогенезисе континентального магматизма: изотопно-геохимические данные по раннепротерозойским пикробазальтам Онежского плато, Балтийский щит // Петрология. 1995. Т. 3. №4.С. 397-419.

4. Суйсарский пикрит-базальтовый комплекс палепротерозоя Карелии (опорный разрез и петрология) / Куликов В.С., Куликова В.В., Лавров Б.С., Писаревский С.А., Пухтель И.С., Соколов С.Я. Петрозаводск: КарНЦ РАН. 1999. 96 с.

5. Тимофеев В.М. Халцедоны острова Суйсари // Тр. Императорского Спб обществава естествоиспытателей. 1912. Т. 35. Вып. 5. С. 157-174.

6. Murata K.J., Norman M.B. An index of crystallinity for quartz // Amer. J. Sci., (1976). V. 276. P. 1120-30. 